\title{
Job Insecurity during an Economic Crisis: the Psychological Consequences of Widespread Corporate Cost-Cutting Announcements
}

\author{
Drake Van Egdom ${ }^{1}$ (1) . Christiane Spitzmueller ${ }^{1} \cdot$ Xueqi Wen $^{2}$. \\ Maryam A. Kazmi ${ }^{1} \cdot$ Erica Baranski $^{3} \cdot$ Rhona Flin $^{4} \cdot$ Ramanan Krishnamoorti $^{5}$
}

Received: 16 April 2021 / Revised: 22 September 2021 / Accepted: 24 September 2021 / Published online: 6 October 2021

This is a U.S. government work and not under copyright protection in the U.S.; foreign copyright protection may apply 2021

\begin{abstract}
Economic crises, such as the one induced by the COVID-19 pandemic, and resulting widespread corporate cost-cutting, drastically alter the nature of work. Job insecurity represents a critical intermediate between the economic ramifications of an economic crisis and work and stress outcomes, however, the underlying cognitive consequences of job insecurity and how to buffer those effects are not well understood. We examine how corporate cost-cutting announcements indirectly relate to employees' attention through their relationship with employee job insecurity and investigate supervisor support as a potential buffer of these relationships. We used multi-source data to test our research model, combining data on cost-cutting announcements (budget cuts, layoffs, and furloughs) in news articles for 165 organizations with survey data from 421 full-time employees from these organizations between March 26, 2020 and April 8, 2020. Cost-cutting announcements are positively related to job insecurity, which is related to employee's attention with supervisor support mitigating the effects of job insecurity on attention. Grounded in self-regulation theories, we contribute to and extend the theoretical understanding of the organizational context for job insecurity and cognitive outcomes. We discuss the implications for organizations to manage and prepare for future economic crises, specifically on organizational communication and supervisor interventions.
\end{abstract}

Drake Van Egdom

davanegd@central.uh.edu

1 Department of Psychology, University of Houston, Houston, TX, USA

2 The Advanced Institute of Business, Tongji University, Shanghai, China

3 Department of Psychology, California State University-East Bay, Hayward, CA, USA

4 Aberdeen Business School, Robert Gordon University, Aberdeen, UK

5 Department of Chemical and Biomolecular Engineering, University of Houston, Houston, TX, USA 
Keywords COVID-19 $\cdot$ Cost-cutting $\cdot$ Job insecurity $\cdot$ Attention

A recent airplane crash (Pakistan International Airlines, 22 May 2020) killed 97 passengers due to pilots distracted by COVID-19 concerns. Flight recorder data showed that the aircraft was mechanically sound and fit to fly. As the pilots approached the tarmac, they were discussing COVID-19 and continued their discussion even after prompts by air traffic control to focus on landing the aircraft (Shahzad, 2020). Although a plane crash is a rare and extreme outcome for attentional deficits, the incident signifies the importance of understanding the many ways in which a global pandemic influences attention at work. Therefore, we use this paper to examine how, when, and why concerns induced by an economic crisis (i.e., COVID-19), such as job insecurity, relate to employee attention and explore how organizations can mitigate the impact of company cost-cutting announcements and job insecurity on employee attention.

COVID-19 constitutes an unprecedented life experience, fundamentally altering the vast majority of peoples' personal and work lives across the globe (World Health Organization, 2020). COVID-19 has been particularly widespread and devastating from a public health and psychological perspective. The International Monetary Fund predicts that the current outbreak will create the worst economic recession since the Great Depression (International Monetary Fund, 2020). More than 22 million individuals filed new jobless claims in the United States alone from March 2020 to the middle of April 2020 with new jobless claims in July 2021 starting to fall back down to levels last seen in March 2020 (Department of Labor, 2021). Job loss puts individuals at risk for adverse health consequences, including increased mortality (Roelfs et al., 2011; Strully, 2009). Individuals and employees alike do not know how long the pandemic will persist, have no control over future outbreaks, and have no way to anticipate the long-lasting effects COVID-19 will have on work (Fouad, 2020). For those who were able to retain jobs during this economic crisis, awareness of company cost-cutting and job insecurity are widespread with likely deleterious consequences for work outcomes and employee health (de Jong et al., 2016; Jiang \& Lavaysse, 2018; Keim et al., 2014; Schumacher et al., 2020).

Job insecurity is defined as "a perceived threat to the continuity and stability of employment as it is currently experienced" (Shoss, 2017, p. 1914). Job insecurity directs employees' cognitive and affective reactions to possible job loss and its consequences. As a result, job insecurity results in adverse emotional responses, such as anger and anxiety (Reisel et al., 2010; Sverke et al., 2002), in addition to effects on general well-being (De Witte et al., 2016; Sverke et al., 2002; Van der Elst et al., 2014). Prior research has incorporated organization-level events to study their effects on job insecurity and outcomes (e.g., bankruptcy; Mohr, 2000; mergers; Lam et al., 2015; van Dick et al., 2006). The current study extends this growing literature by examining potential mechanisms for mitigating job insecurity's negative effects on attention during a widespread economic crisis in 2020 affecting numerous organizations. 
From a theoretical perspective, self-regulation theories provide a useful framework for understanding this phenomenon. One of the central tenets of these theories is that stress and rumination can result in an insufficient ability to regulate attention and reduce the ability of individuals to pay attention to their work tasks (Beal et al., 2005). In the current study, job insecurity is conceptualized as worrying about one's job and the future of one's career. The widespread cost-cutting announcements stemming from the COVID-19 induced economic crisis likely exacerbates the rumination and stress resulting from job insecurity. In sum, the current study draws on self-regulation theories, such that employees may have an even harder time focusing on their job tasks if the stress and rumination stemming from job insecurity takes their attention away from their work. Given the critical role of cognition for efficient and safe task execution (Sneddon et al., 2013; Sundfør et al., 2019; Wallace \& Chen, 2005), the limited focus on attention in the job insecurity literature represents a critical research gap. Hence, we use self-regulation theories as a foundation for exploring whether widespread company cost-cutting and consequent job insecurity during the pandemic is linked to attention as proposed by self-regulation theories (Beal et al., 2005).

We contribute to the understanding of job insecurity and attention by addressing two knowledge gaps. First, we examine job insecurity from employees in numerous organizations in an industry hit hard by an economic crisis, whereas most research examines the effects of events on job insecurity at a single organization (e.g., Mohr, 2000). Economic crises occur frequently around the world (e.g., Great Recession of 2007-2009). Our study examines how these events can impact employees in a multitude of organizations within the same industry. We expect that employees' job insecurity and outcomes will be worse during an economic crisis as they have fewer options if they are laid off. Moreover, our paper heeds a recent call from occupational health experts to study how supervisors can support workers at a time of economic stress (Sinclair et al., 2020). Second, we extend self-regulation theories (Beal et al., 2005) to demonstrate how societal and organizational events shape employee perceptions of job insecurity and attention. Hence, this study expands the criterion space for job insecurity by examining its relation to cognitive mechanisms, specifically attention.

The remainder of the introduction is structured as follows. We introduce the implications of organization-level events for job insecurity. Next, we discuss selfregulation theories to understand the relationships of environmental change, job insecurity, and attention. Last, we examine perceived supervisor support as a buffer that can potentially protect individuals from the negative effects of company costcutting announcements and job insecurity.

\section{Organizational Cost-Cutting Announcements}

Throughout the COVID-19 economic crisis, organizations have engaged in extensive cost-cutting measures. We define these cost-cutting measures as organizations reducing their spending, including budget cuts, furloughs, and layoffs. COVID-19 induced unemployment has continued throughout the pandemic as control of the 
virus is still far removed in many countries. In some hard-hit industries (e.g., oil and gas), employees may be concerned about losing their jobs as they may not easily find employment if alternate employers are also cutting costs. Within self-regulation theories (Beal et al., 2005), these cost-cutting announcements represent an event that may elicit job insecurity related stress and rumination.

Widespread cost-cutting during an economic crisis represents a very strong situation, such that the event is disruptive and critical. The backdrop of COVID-19 highlights the relevance of organizational cost cutting, especially for industries driven by consumer demand (e.g., oil prices). Further, COVID-19 has disrupted the global economy with organizations having to adjust their entire operations to ensure their workforce's safety and the long-term profitability of their organization. The remaining employees of an organization that announces cost-cutting initiatives must change their work and procedures to alleviate the loss of financial resources and human capital.

Keim et al.'s (2014) meta-analytic work shows organizational change, such as downsizing and layoffs, has a modest, positive relationship with job insecurity. Selfregulation theories provide a useful framework for understanding this relationship. Cost-cutting announcements likely increase an employee's thoughts on the stability of their employment, which are represented as off-task attentional demands in selfregulation theories (Beal et al., 2005). As COVID-19 has forced whole industries to enact cost-cutting measures, these events have grown more common. In the current study, employees in organizations cutting costs will likely view their current employment as more threatened.

Hypothesis 1: Company cost-cutting announcements, including layoffs, furloughs, and budget cuts, will be positively related to job insecurity.

\section{Job Insecurity and Attention}

The experience of job insecurity is associated with cognitive reactions, such as worrying about precarious employment and financial responsibilities and pondering future career prospects. However, the literature on the cognitive mechanisms of job insecurity is incomplete as they are not fully specified in the literature. Essentially, job insecurity is related to safety outcomes (Jiang \& Lavaysse, 2018) and attention is related to safety outcomes (Jin et al., 2021; Sneddon et al., 2013; Sundfør et al., 2019; Wallace \& Chen, 2005; Wallace \& Vodanovich, 2003); however, limited prior research has focused on how job insecurity is related to attention. Attention represents a critical cognitive piece. We define attention as, "a state in which cognitive resources are focused on certain aspects of the environment rather than on others" (APA, n.d.). The current study uses attention as an outcome due to its importance and centrality as a cognitive mechanism in work tasks.

As self-regulation theories suggest, job insecurity represents a threat to an employee's expectations for future employment, which triggers stress and rumination that may enhance or reduce employee attention. Conflicting motivations may play a part in job insecurity affecting attention (Cheng \& Chan, 2008; Shoss, 2017; 
Sverke \& Hellgren, 2002). Job insecurity could motivate individuals to focus on their work tasks to show supervisors that they deserve to stay in the company. Conversely, job insecurity could trigger thoughts of future career prospects or financial insecurity, limiting their ability to attend to work tasks. Although theoretical arguments can be made that job insecurity either improves or impairs attention, metaanalyses present enough evidence that job insecurity impedes work performance and safety (Cheng \& Chan, 2008; Jiang \& Lavaysse, 2018). Employees likely cannot focus on their work tasks as they ruminate about their job being threatened. As a result, we align our hypothesis on the effect of job insecurity on attention with self-regulation theory and empirical evidence. An individual facing a threat to their employment will have less attention for changes in their environment as they will be ruminating about their employment situation. As self-regulation theories suggest, we hypothesize that job insecurity will reduce attention.

Hypothesis 2: Job insecurity will be negatively related to attention.

Furthermore, we expect cost-cutting announcements to indirectly relate to attention through job insecurity. Cost-cutting announcements represent a distal event, and job insecurity is a more proximal effect on attention. As self-regulation theory suggests, cost-cutting announcements will likely trigger an individual to perceive their job as threatened (i.e., job insecurity), which increases their off-task attentional demands and reducing their ability to attend to work tasks. In sum, we expect job insecurity to mediate the relationship between company cost-cutting announcements and attention.

Hypothesis 3: Company cost-cutting announcements will be indirectly related to attention through job insecurity.

\section{Supervisor Support as a Buffer}

The current COVID-19 economic crisis and mass cost-cutting announcements force employees to simultaneously adapt to work changes and increased job insecurity. Due to the serious implications of attention for work and health outcomes (Jiang \& Lavaysse, 2018), mitigation strategies are necessary. Supervisors represent one of the most critical features in an individual's work environment due to their control over important resources and personnel-related decision-making authority. Perceived supervisor support is defined as an employee's evaluation of how much their supervisor values them and cares about their well-being (Eisenberger et al., 2002). During an economic crisis, the role of supervisors is even more critical due to their function as a gatekeeper to organizational resources, reducing their team's stress, and improving their employee's work outcomes (Sinclair et al., 2020). A supervisor could schedule weekly check-in meetings to ensure their employees' well-being, or they could be flexible with when and how employees complete their work. Within the self-regulation theoretical framework, supervisors may influence the extent to which an event creates job insecurity related rumination and how much that 
rumination pulls the employee's attention away from work-related tasks. As a result, perceived supervisor support provides one potential mechanism for mitigating the effects of cost-cutting announcements during an economic crisis.

Social support, especially supervisory support, has been theorized as an important moderator of the relationship between job insecurity and its outcomes (Lee et al., 2018). Social support has exhibited a main effect on job insecurity (Jiang \& Lavaysse, 2018) and is a moderator between job insecurity and job performance (Schreurs et al., 2012) and a moderator between occupational injury and job insecurity (Lawrence et al., 2013). The current study aligns with Lee et al.'s (2018) theoretical model to examine perceived supervisor support as both a buffer of cost-cutting announcements on job insecurity and job insecurity on attention. After organizations announce cost-cutting announcements, supervisors may help employees interpret the event as less of a threat to their employment. For example, the supervisor can specifically reassure them that their job is not in jeopardy and the cost-cutting announcement does not pertain to them. If employees still perceive the event as a threat, supportive supervisors can mitigate the effects on attention by helping employees pay attention to their job tasks and ruminate less. As an example, the supervisor could have more task-specific conversations to encourage them to focus.

Further, the indirect effect of cost-cutting announcements on attention through job insecurity will depend on perceived supervisor support due to supervisors representing an integral piece of an employee's work environment. Supervisors are present both during and after cost-cutting announcements, which allows them to influence the employee's processing of these changes and ensuring job insecurity perceptions do not impact their work.

Hypothesis 4a. Perceived supervisor support will moderate the relationship between company cost-cutting announcements and job insecurity, such that the relationship will be stronger when perceived supervisor support is low.

Hypothesis $4 b$. Perceived supervisor support will moderate the relationship between job insecurity and attention, such that the relationship will be stronger when perceived supervisor support is low.

Hypothesis 4c. Perceived supervisor support will moderate the indirect effect of company cost-cutting announcements on attention through job insecurity with perceived supervisor support moderating both the effect of company cost-cutting on job insecurity and job insecurity on attention, such that the indirect effect will be stronger when perceived supervisor support is low.

\section{Method}

\section{Sample and Data Collection Procedures}

In partnership with two industry associations, we gathered data from a broad crosssection of workers in the USA employed in the energy sector, resulting in responses from 421 full-time employees from 165 organizations. Data collection was approved by the University of Houston's Institutional Review Board (IRB \#: 02229). 
Participants from industry association A filled out the survey from March 30, 2020 to April 8, 2020, with 96.2\% filling out the survey from March 30, 2020 to April 1, 2020. Industry association B filled out the survey from March 26, 2020 to April 7, 2020 with much more variability in the days they filled out the survey (e.g., March 26, 2020 to March 28, 2020=43.8\%, March 30, 2020 to April 1, 2020=40.0\%, and April 7, 2020 $=8.1 \%$ ). We did not expect survey data quality to differ for those filling out the survey early than those who needed reminders and filled out the survey later (Ingels, 2020).

The organizations and employees represent a wide range of sub-sectors involved in producing and selling energy with organizations varying widely in size. The two industry associations sent email invitations to their members and requested they complete an anonymous survey. Participants entered raffle drawings for $10 \$ 100$ Amazon gift cards. The current data is part of a broader study on the outlook of the energy industry in response to COVID-19. To ensure the sampling method did not affect our results, we included control variables detailed below and utilized Unconstrained Product Indicator analysis due to potential non-normality in the distribution (Marsh et al., 2007). The Mplus code can be found in Appendix 1.

\section{Participant Demographics}

A majority of the participants identified as white (65\%) and as women (64\%). On average, participants had worked 15.7 years in the energy industry and were 43 years old. $40 \%$ of participants worked for companies where cost-cutting initiatives had been announced in the news across 35 different companies. Sample job titles of participants included mechanical engineer, process engineer, and health and safety specialist.

\section{Measures}

The survey content was developed in partnership with industry associations and measures for this paper, which were embedded in a more extensive survey to meet industry partner associations' information needs and our study's needs. Given total survey length restrictions, we adapted validated scales using Stanton et al.'s (2002) guidelines. As discussed in Heggestad et al.'s (2019) review of scale adaptation practices, we focused on retaining critical scale features. Specifically, we focused on maintaining content validity by ensuring all aspects of construct definitions were addressed through the items used. We pilot-tested the instrument with employees of our industry association partners and further adapted items based on feedback. Measures were adapted to make them specific to this economic crisis context by including phrases such as '... during COVID-19'. Unless otherwise indicated, participants responded to items using a 5-point Likert-type scale ranging from strongly disagree (1) to strongly agree (5). Participants took an average of 8-10 min to complete the survey. 


\section{Job Insecurity Measure and Validation Study}

We adapted Van der Elst et al.' (2014) short job insecurity scale to the COVID19 context, and we use one of their items and modify the other two based on our industry partners' input to reflect cognitive and affective job insecurity (Jiang \& Lavaysse, 2018). The final items used were "I feel insecure about the future of my job because of COVID19," "I expect significant changes in my employment situation in the next six months due to COVID-19," and "I am worried about paying my mortgage and other necessities during the next year."

To ensure the adapted job insecurity scale was reliable and valid, we surveyed and conducted supplemental analyses on a separate sample of energy industry employees $(N=299)$ from April 27, 2020 to May 7, 2020. We used the above three-item job insecurity scale in this study and examined three additional nonadapted job insecurity items from Van der Elst et al.'s (2014) scale: "Chances are I will soon lose my job," "I think I might lose my job in the near future," and reverse-coded "I am sure I can keep my job." Then, we created two scales: one scale had the three items adapted for the industry associations and the second scale had only the three items from Van der Elst et al. (2014). To examine the three-item adapted scale's reliability and validity, we conducted three analyses: reliability analyses, correlated the two scales, and correlated job insecurity with attention. The three-item scale $(\alpha=.70)$ adapted for the industry associations and scale with three items from Van der Elst et al. $(2014 ; \alpha=.87)$ were both reliable, and the two scales were strongly correlated $(r=.72)$. These two analyses indicate that the adapted three-item adapted scale is reliable and closely related to the non-adapted items. Further, the correlation between the adapted three-item scale and attention $(r=.32)$ and the Van der Elst et al. (2014) items and attention $(r=.23)$ are highly similar, which provides evidence that the three-item scale exhibits similar criterion validity to the six-item scale for attention.

\section{Company Cost-Cutting Announcement}

Cost-cutting was measured using independent news reports about cost-cutting announced by participants' respective employers. To ensure participant confidentiality and cooperation and to use researcher-coded cost-cutting indicators rather than self-reports, we did not ask participants for their company's cost-cutting practices. For each company, graduate and undergraduate student research assistants served as raters, and raters calibrated ratings to achieve consistency in coding through discussions. They conducted Google searches and coded for the announcement of budget cuts, layoffs, or furloughs. We compared the date of the media article and the date the respondent took the survey. We only coded that the participants were exposed to a cost-cutting announcement if the respondent completed the survey after the date of the media article. To ensure the company costcutting was due to COVID-19, we only searched for public news releases from March 1, 2020 to April 8, 2020 as the pandemic was increasing in strength. The variable was coded as binary as yes (1) or no (0) if any cost-cutting announcement 
(budget cuts, layoffs, or furloughs) occurred before the participant completed the survey or if the company did not have a cost-cutting announcement. First, five raters were trained on the protocol and all five rated nine companies with $83 \%$ accuracy. Then, the rest of the companies were split between the five raters and a final rater went through each coded news article to ensure reliability.

\section{Perceived Supervisor Support}

Perceived supervisor support was measured with three items $(\alpha=.91$; Eisenberger et al., 2002). The three items were: "My supervisor cares about my opinion," "My supervisor really cares about my well-being," and "My supervisor strongly considers my goals and values."

\section{Attention}

We adapted three items $(\alpha=.81)$ from the attentional component of a work situation awareness scale (Sneddon et al., 2013) to be COVID-19 specific. The three items on attentional failures are: "Since the COVID-19 outbreak started, I often have difficulty paying close attention to details, which results in careless errors," "Since the COVID19 outbreak started, I often find myself speaking or acting without thinking," and "Since the COVID19 outbreak started, when I finish reading or being told instructions, I often have to re-read them or ask for them to be repeated as I don't remember them." The three items were reverse-coded to represent attention and ease interpretability.

\section{Demographic Covariates}

We determined our selection of covariates based on theoretical relevance and past research (Bernerth \& Aguinis, 2016). We included self-reported gender $(0=$ man, $1=$ woman), partner (yes/no), the number of hours partner worked per week, and the number of children, as these variables were likely to covary with the variables of interest. Keim et al. (2014) note inconsistent findings in the literature with gender, so we include gender as a covariate to account for these potential differences. Employees with partners, especially partners working more hours, may experience fewer consequences of cost-cutting as their partners contribute to their family's income. Similarly, employees with children and more children may experience worse consequences with costcutting announcements as they have more financial commitments. We also included company size and sample source. Company size was manually coded using public information available online about the respondents' companies. The U.S. Department of Labor requires larger organizations to announce cost-cutting through the Worker Adjustment and Retraining Notification Act (WARN) of 1988 (29 USC 2100 et. seq.), "Protects workers, their families and communities by requiring most employers with 100 or more employees to provide notification 60 calendar days in advance of plant closings and mass layoffs." Our survey was distributed through two industry associations, so including the source and company size allowed us to account for any systematic differences across the companies and two samples. 


\section{Results}

\section{Measurement Model}

Table 1 presents descriptive statistics and bivariate correlations. We used full information maximum likelihood (FIML) estimation throughout to deal with missing data given its superior performance to alternatives (e.g., listwise deletion; Enders \& Bandalos, 2001) and missing data guidelines (Newman, 2014) suggest using all available data. Prior to testing our hypotheses, we performed a series of confirmatory factor analyses at the individual level to test the measurement model specifying job insecurity, perceived supervisor support, and attention.

The three-factor model provided good fit $\left(\chi^{2}=38.11, d f=24, p<.05 ; C F I=.99\right.$, $T L I=.99, R M S E A=.04, S R M R=.03)$ and fit the data better than the best-fitting two-factor model $\left(\chi^{2}=436.79, d f=26, p<.001 ; C F I=.79, T L I=.70, R M S E A=.20\right.$, $S R M R=.13)$, and a one-factor model $\left(\chi^{2}=1259.71, d f=27, p<.001 ; C F I=.26\right.$, $T L I=.14, R M S E A=.33, S R M R=.21$; see Table 2).

\section{Hypothesis Testing}

We used the Unconstrained Product Indicator (UPI; Marsh et al., 2007) approach with Mplus 8.0 (Muthén \& Muthén, 2017) to test the hypothesized moderated mediation model. In our study, cost-cutting announcements is a binary variable and two of the three perceived supervisor support indicators are negatively skewed and positively kurtotic (skewness $=-1.44$ and -1.49 , respectively; kurtosis $=1.79$ and 1.96 , respectively). In this case, the normality of the indicators cannot be assumed. In contrast, the UPI approach does not impose any constraints based on the normality assumption (Marsh et al., 2004). As such, the UPI approach is more appropriate to use and can provide less biased results in our study (Marsh et al., 2004). Because we are dealing with latent variables, we utilized the UPI approach to create indicators for the interaction terms (Marsh et al., 2004).

Following the steps recommended by Marsh et al. (2007), we first centered company cost-cutting announcements, the indicators of job insecurity, and the indicators of perceived supervisor support by their grand means. Next, utilizing the matched pair strategy, we created the product indicators for the interaction of company costcutting announcement with perceived supervisor support and interaction of job insecurity with perceived supervisor support (Marsh et al., 2004). In specific, the indicators of company cost-cutting announcement/job insecurity were paired and multiplied with the indicators of perceived supervisor support based on their reliabilities. Also, each of the indicators was used only once when forming the product indicators of the latent interaction factors (Marsh et al., 2004). More detailed information on our use of the matched pair strategy can be found in Appendix 2.

As compared to other latent variable interaction modeling approaches, such as Latent Moderated Structural Equations (LMS; Klein \& Moosbrugger, 2000) and Constrained Product Indicator (CPI; Jöreskog \& Yang, 1996), the UPI approach 


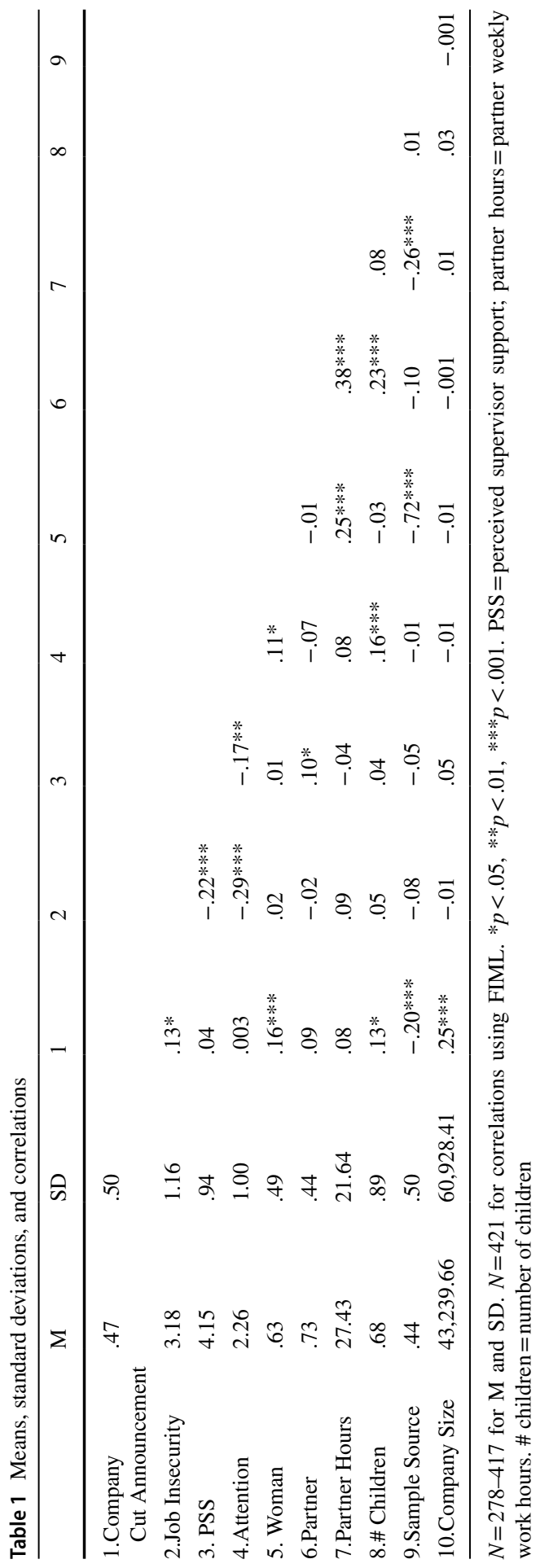




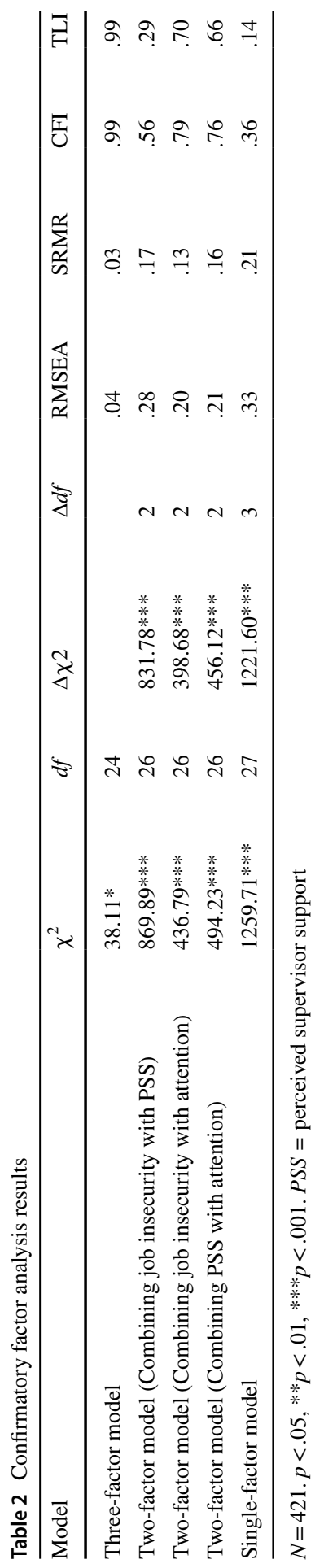


provides more reliable latent interaction estimates when the assumption of normality is violated (Cham et al., 2012). Considering that the participants came from different organizations and the focus of the current study is how company cost-cutting may affect individual employees, we used "Type = Complex" syntax in Mplus that adjusted standard errors using a sandwich estimator to account for the nested nature of the data (Muthén \& Muthén, 2017). Finally, Monte Carlo resampling method was used to estimate the indirect effect and the conditional indirect effects (Preacher \& Selig, 2012).

To assess the main effects and indirect effect, we first tested a mediation model where perceived supervisor support was not included as a moderator. The indirect effects are reported in Table 3. The model provides a good model fit $\left(\chi^{2}\right.$ $(36)=52.86, p<.05 ; C F I=.98, T L I=.97, R M S E A=.03, S R M R=.03)$. Consistent with hypothesis 1 , company cost-cutting announcements is significantly associated with job insecurity $(b=.30, S E=.14, p<.05)$. Hypothesis 2 is that job insecurity is negatively associated with attention, which is supported $(b=-.24$,

Table 3 Summary of results of the mediation model

\begin{tabular}{|c|c|c|c|}
\hline Effect type & $\begin{array}{l}\text { Unstandardized } \\
\text { coefficient }\end{array}$ & $S E$ & $95 \% C I$ \\
\hline \multicolumn{4}{|l|}{ Direct Path } \\
\hline \multicolumn{4}{|l|}{ Job Insecurity } \\
\hline Company cut announcement $\rightarrow$ Job insecurity & $.30 *$ & .14 & {$[.03, .57]$} \\
\hline Woman $\rightarrow$ Job insecurity & -.29 & .13 & {$[-.59, .001]$} \\
\hline Partner $\rightarrow$ Job insecurity & -.18 & .08 & {$[-.44, .08]$} \\
\hline Number of hours partner worked $\rightarrow$ Job insecurity & $.01 *$ & .003 & {$[.001, .01]$} \\
\hline Number of children $\rightarrow$ Job insecurity & .04 & .07 & {$[-.09, .17]$} \\
\hline Company size $\rightarrow$ Job insecurity & .00 & .001 & {$[-.003, .002]$} \\
\hline Source $\rightarrow$ Job insecurity & $-.32 *$ & .16 & {$[-.63,-.01]$} \\
\hline \multicolumn{4}{|l|}{ Attention } \\
\hline Job insecurity $\rightarrow$ Attention & $-.24 * * *$ & .03 & {$[-.30,-.17]$} \\
\hline Company cut announcement $\rightarrow$ Attention & .12 & .10 & {$[-.07, .31]$} \\
\hline Woman $\rightarrow$ Attention & $-.40 * * *$ & .10 & {$[-.60,-.21]$} \\
\hline Partner $\rightarrow$ Attention & $.24 * *$ & .08 & {$[.07, .41]$} \\
\hline Number of hours partner worked $\rightarrow$ Attention & -.003 & .002 & {$[-.01, .001]$} \\
\hline Number of children $\rightarrow$ Attention & $-.18 * * *$ & .04 & {$[-.26,-.09]$} \\
\hline Company size $\rightarrow$ Attention & .00 & .001 & {$[-.001, .001]$} \\
\hline Source $\rightarrow$ Attention & $-.30^{* *}$ & .10 & {$[-.49,-.11]$} \\
\hline \multicolumn{4}{|l|}{ Indirect Effect } \\
\hline \multicolumn{4}{|l|}{$R^{2}$} \\
\hline Job insecurity & .05 & & \\
\hline Attention & $.20 * * *$ & & \\
\hline
\end{tabular}

$N=421 . * p<.05, * * p<.01, * * * p<.001$ 
$S E=.03, p<.001)$. Hypothesis 3 proposed that company cost-cutting announcements are associated with attention indirectly through job insecurity. To estimate the indirect effect, we adopted the parametric bootstrapping approach using an R-web utility developed by Selig and Preacher (2009) to yield asymmetric confidence intervals (CIs). The 20,000-repetition Monte Carlo tests indicated that job insecurity mediated the relationship of company cost-cutting announcements with attention (Unstandardized Indirect Effect $=-.07,95 \%$ CI $[-.12,-.004]$ ). Hypothesis 3 is supported.

Next, we ran the moderated mediation model to assess the moderating effects and conditional indirect effects. The model provided a good fit to the data $\left(\chi^{2}\right.$ $(116)=186.85, p<.001 ; C F I=.97, T L I=.95, R M S E A=.04, S R M R=.04)$. Figure 1 presents the SEM results for all the model paths. Hypothesis 4 a stated that perceived supervisor support moderates the relationship between company costcutting announcements and job insecurity, such that the relationships are stronger when perceived supervisor support is low. However, perceived supervisor support does not moderate the relationship between company cost-cutting announcements and job insecurity $(b=.02, S E=.04, n s)$. Hypothesis 4 a is not supported.

Hypothesis $4 \mathrm{~b}$ stated that perceived supervisor support moderates the relationship between job insecurity and attention, such that the relationships are stronger when perceived supervisor support is low. Figure 2 presents the simple slopes of the relationships of job insecurity with attention. Perceived supervisor support moderates the relationships between job insecurity and attention $(b=-.15, S E=.07, p<.05)$. The relationships of job insecurity with attention are stronger at higher levels of perceived supervisor support $(b=-.36, S E=.07, p<.001)$ than at lower levels of perceived supervisor support $(b=-.07, S E=.09, n s)$. Hypothesis $4 \mathrm{~b}$ is not supported as

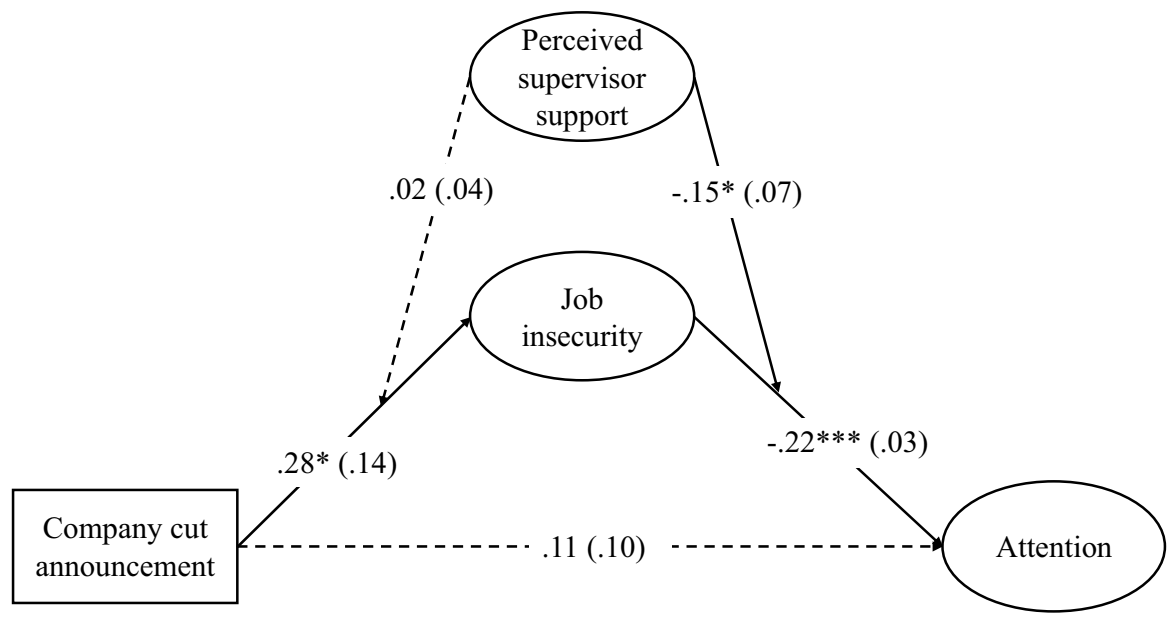

Note. ${ }^{*} p<.05 ; * * p<.01 ; * * * p<.001$. Unstandardized coefficients are reported; Standard errors are shown in the parentheses.

Fig. 1 The Moderated Mediation Model 


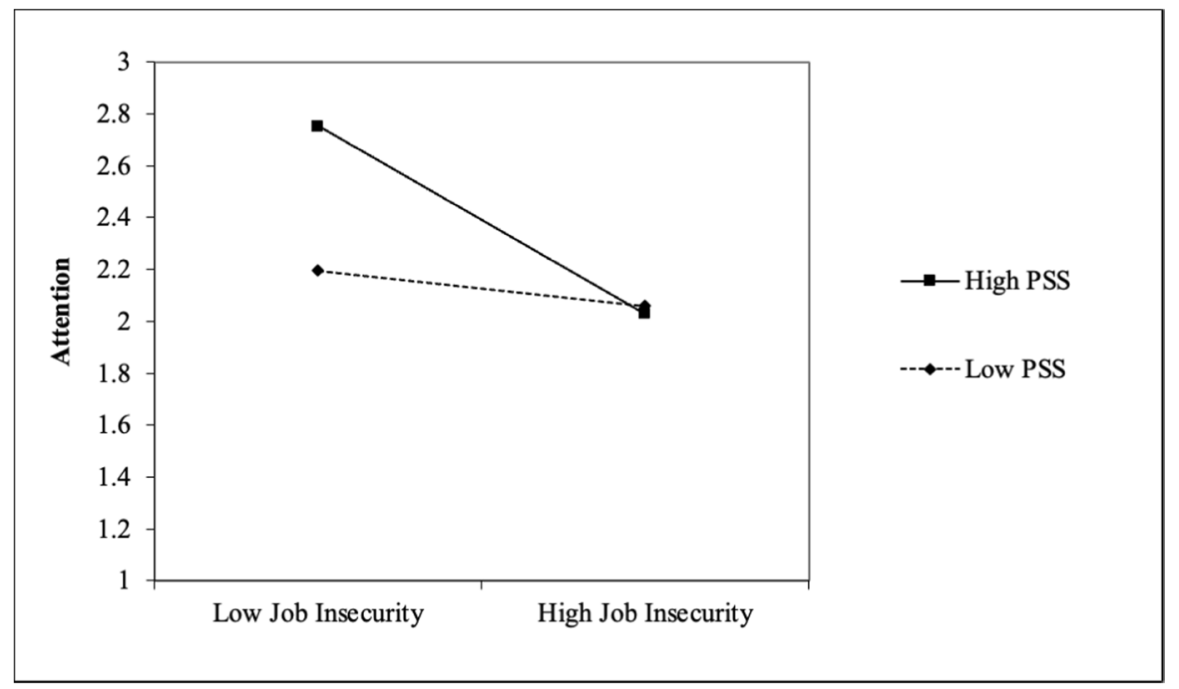

Fig. 2 The moderation effect of perceived supervisor support (PSS) on the relationship between job insecurity and attention

the interaction effect is not in the hypothesized direction. Perceived supervisor support only resulted in improved attention when job insecurity was lower.

Hypothesis $4 \mathrm{c}$ proposed that the conditional indirect effect of company cost-cutting announcements on attention via job insecurity will be stronger when perceived supervisor support is low. The conditional indirect effects are reported in Table 4. Hypothesis $4 \mathrm{c}$ is not supported as the effects are in the opposite direction with higher values of perceived supervisor support resulting in stronger indirect effects.

Although the findings seem to be inconsistent with Hypotheses $4 \mathrm{~b}$ and $4 \mathrm{c}$, the results suggest that attention levels are generally higher when perceived supervisor support is high compared to when supervisor support is low. Moreover, at low job insecurity, high levels of supervisor support largely enhance attention, indicating the potential benefits of perceived supervisor support for employees low in job insecurity.

Lastly, some of the covariates were significant in Table 4. Women had lower attention $(b=-.38, S E=.10, p<.001)$, those with partners had higher attention $(b=.21, S E=.09, p<.05)$, and attention decreased with the number of children $(b=-.18, S E=.04, p<.001)$. COVID-19 and the forced transition to remote work may explain these effects as their work and family boundaries are blurred. On average, women take on more of the childcare and household labor, including cognitive labor (Daminger, 2019; Lachance-Grzela \& Bouchard, 2010). This lopsided division of labor may distract them more than men, along with more children adding more distractions. Employees with a partner may be able to better balance their work and family responsibilities, allowing them to pay more attention at work. The source covariate is also significant for job insecurity $(b=-.30, S E=.15, p<.05)$ and attention $(b=-.23, S E=.10, p<.05)$. The sample characteristics of each source may 
Table 4 Summary of results of the moderated mediation model

\begin{tabular}{|c|c|c|c|}
\hline Effect type & $\begin{array}{l}\text { Unstandardized } \\
\text { coefficient }\end{array}$ & $S E$ & $95 \% C I$ \\
\hline \multicolumn{4}{|l|}{ Direct Path } \\
\hline \multicolumn{4}{|l|}{ Job Insecurity } \\
\hline Company cut announcement $\rightarrow$ Job insecurity & $.28 *$ & .14 & {$[.01, .55]$} \\
\hline PSS $\rightarrow$ Job Insecurity & .08 & .09 & {$[-.09, .25]$} \\
\hline Company cut announcement $\times$ PSS $\rightarrow$ Job insecurity & .02 & .04 & {$[-.06, .10]$} \\
\hline Woman $\rightarrow$ Job insecurity & -.28 & .15 & {$[-.57, .004]$} \\
\hline Partner $\rightarrow$ Job insecurity & -.21 & .13 & {$[-.47, .05]$} \\
\hline Number of hours partner worked $\rightarrow$ Job insecurity & $.01 *$ & .003 & {$[.001, .01]$} \\
\hline Number of children $\rightarrow$ Job insecurity & .04 & .06 & {$[-.08, .16]$} \\
\hline Company size $\rightarrow$ Job insecurity & -.001 & .001 & {$[-.003, .002]$} \\
\hline Source $\rightarrow$ Job insecurity & $-.30^{*}$ & .15 & {$[-.59,-.001]$} \\
\hline \multicolumn{4}{|l|}{ Attention } \\
\hline Job insecurity $\rightarrow$ Attention & $-.22 * * *$ & .03 & {$[-.28,-.15]$} \\
\hline Company cut announcement $\rightarrow$ Attention & .11 & .10 & {$[-.08, .30]$} \\
\hline $\mathrm{PSS} \rightarrow$ Attention & $.13^{*}$ & .05 & {$[.03, .23]$} \\
\hline PSS $\times$ Job insecurity $\rightarrow$ Attention & $-.15^{*}$ & .07 & {$[-.28,-.01]$} \\
\hline Woman $\rightarrow$ Attention & $-.38 * * *$ & .10 & {$[-.58,-.18]$} \\
\hline Partner $\rightarrow$ Attention & $.21 *$ & .09 & {$[.04, .38]$} \\
\hline Number of hours partner worked $\rightarrow$ Attention & -.002 & .002 & {$[-.01, .002]$} \\
\hline Number of children $\rightarrow$ Attention & $-.18 * * *$ & .04 & {$[-.26,-.10]$} \\
\hline Company size $\rightarrow$ Attention & .00 & .001 & {$[-.001, .001]$} \\
\hline Source $\rightarrow$ Attention & $-.23 *$ & .10 & {$[-.43,-.03]$} \\
\hline \multicolumn{4}{|l|}{ Conditional Indirect Effect } \\
\hline Low PSS $(-1 S D)$ & -.02 & .02 & {$[-.08, .03]$} \\
\hline Medium PSS (Mean) & $-.06^{*}$ & .03 & {$[-.12,-.002]$} \\
\hline High PSS (+1 SD) & $-.11 *$ & .06 & {$[-.24,-.01]$} \\
\hline \multicolumn{4}{|l|}{$R^{2}$} \\
\hline Job insecurity & .01 & & \\
\hline Attention & $.24 * * *$ & & \\
\hline
\end{tabular}

$N=421 . * p<.05, * * p<.01, * * * p<.001 . P S S=$ Perceived Supervisor Support

explain some of these effects as one of the industry associations had a much higher sample of women and the employee's partners worked more hours.

\section{Discussion}

The uncertainty from cost-cutting during an economic crisis emphasizes that more research is needed to illuminate how employees interpret widespread organizational events and how these events affect employee cognitive outcomes, such as attention. Past studies focused on individual organizations undergoing 
bankruptcy (e.g., Mohr, 2000) or mergers (e.g., Lam et al., 2015; van Dick et al., 2006), however economic crises occur at a more macro scale and impact a multitude of organizations. The impact of job insecurity on cognitive processes are not as well-understood with the current study contributing to filling this gap. Drawing on self-regulation theories, we explored cost-cutting announcements' indirect effect and job insecurity's direct effect on attention. We further examined perceived supervisor support as a potential mechanism for buffering the effects of cost-cutting on job insecurity and job insecurity on attention.

In the current study, we hypothesized that cost-cutting announcements during an economic crisis would lead to employees interpreting their employment situation as threatened and experience job insecurity. In line with Hypothesis 1, costcutting announcements increase job insecurity, which extends previous findings by examining an industry hard hit by an economic crisis. Second, we expected job insecurity to decrease attention based on self-regulation theories (Beal et al., 2005). Job insecurity likely triggers off-task attentional demands that make paying attention at work harder for employees. Hypothesis 2 was supported with job insecurity being negatively related to attention, which indicates that job insecurity may impact attention. Our Hypothesis 3 extends the first two hypotheses by testing the indirect effect of cost-cutting announcements on attention through their perceptions of their job being threatened. This expectation was supported, which indicates that cost-cutting announcements affect the attention of remaining employees via their job insecurity. This finding supports self-regulation theories by showing that cost-cutting announcements elicit off-task attentional demands that impact attention.

We extend prior research (Lawrence et al., 2013; Schreurs et al., 2012) showing supervisors represent important features of an employee's environment. For Hypothesis $4 \mathrm{a}$, we anticipated that higher perceived supervisor support would strengthen the relationship between cost-cutting announcements and job insecurity, however this moderation effect of supervisor support on job insecurity and attention was not supported. Instead, perceived supervisor support directly reduced job insecurity regardless of the organization's cost-cutting announcements, indicating that supervisors may be generally important for reducing job insecurity. Hypothesis $4 \mathrm{~b}$ proposed lower perceived supervisor support as strengthening the relationship between job insecurity and attention. This hypothesis was not supported; job insecurity during an economic crisis may be too strong to be alleviated by general supervisor support. Individuals low on job insecurity had increased attention when supervisors supported them. Supervisor support may be less effective for employees with high job insecurity due to highly dissonant information. The organization signals that the individual's employment is threatened, yet the supervisor continues to be supportive. Thus, inconsistent messaging may limit the employees' ability to attend to their work environment. Essentially, perceived supportive supervision can only improve employee's attention if the employee is not preoccupied with the instability and uncertainty of their job.

Lastly, we expected perceived supervisor support to moderate the indirect effect of cost-cutting announcements on attention via job insecurity (Hypothesis 4c). This effect was not supported for the above reason that job insecurity during an economic 
crisis may be too strong for the supervisor's general support to be effective. In summation, these results extend the job insecurity literature and self-regulation theories by showing that cost-cutting announcements during an economic crisis affect employee attention through their job insecurity. Additionally, general supervisor support may not be enough to mitigate the attention-pulling effects of cost-cutting during an economic crisis.

\section{Practical Implications}

Our findings point to two key practical implications for organizations during the COVID-19 economic crisis and in future economic crises. First, organizations can help employees in the sensemaking process to interpret their employment situation as secure. When organizations announce cost-cutting measures, employees will be more likely to interpret their current job as threatened, resulting in reduced attention and likely worse work and health outcomes (e.g., de Jong et al., 2016; Jiang \& Lavaysse, 2018). Potential solutions include providing effective organizational communication with an emphasis on transparency with employees about the reasons behind the cost-cutting (Keim et al., 2014). Our study did not find perceived supervisor support to be effective in increasing attention when job insecurity is high. Employees may be particularly affected by the widespread economic crisis, such that general supervisor support may not ease their concerns. Although this finding is unexpected, future research could focus on more domain-specific supervisor support and trainings. For example, family supportive supervisor behavior training (Odle-Dusseau et al., 2016) and supervisor mental health training (Dimoff \& Kelloway, 2019) provide evidence for domain-specific supervisor training to impact outcomes and general frameworks for future interventions that specifically target attention. Second, organizations need to be prepared to mitigate the potential impact of reduced attention to ensure the best outcomes for their employees and the organization. One potential mechanism would be an online employee workplace mindfulness intervention, which could help minimize job insecurity related rumination (Aikens et al., 2014).

\section{Limitations and Future Directions}

Despite our study's contributions, several study limitations should be addressed in subsequent research. First, our entire sample was drawn from the energy industry, which includes employees from 165 different companies in an essential industry hit hard by cost-cutting initiatives. Future research is needed to better understand other industries hit hard by the pandemic (e.g., retail) that provide workers with lower wages than energy industry jobs and make them vulnerable to the consequences of job loss. Although the data was collected from multiple organizations, the average cluster size is 2.51 , which may not be sufficient for a multilevel analysis. Further, the ICC[1] of attention is .01, which suggests that attention may not be aggregated at the between-level. Taken together, it may not be appropriate for our study to estimate 
the effects at the organizational level. Future research should obtain a larger sample size from each organization to identify firm-level contextual variables.

Second, our data were obtained in partnership with industry associations, which limited our ability to use full-length measures. We conducted a supplementary analysis for job insecurity using a separate sample to replicate the reliability and validity compared to a full scale. Consistent with Heggestad et al. (2019) recommendations, we recommend our findings be replicated and extended using the full-length scales. A strength of the study was our ability to obtain rapid access to respondents during a two-week timeframe as COVID-19 cases were quickly increasing, large numbers of employers were cutting costs, and obtain researcher-coded data on cost-cutting initiatives in 165 organizations. Future research should include self-report data on employee awareness of company cost-cutting practices to provide additional evidence for coding news reports.

Third, our study did not include all possible cognitive mechanisms and focused only on attention. Future research is needed to better understand how other cognitive components are important for task execution (e.g., working memory and decision making) are affected. The nomological network of attention needs to be clarified as attention is a narrower component or precursor of similar constructs, such as cognitive functioning (Fisher et al., 2019) and self-regulation failure (Baumeister \& Heatherton, 1996). Fourth, we did not distinguish between quantitative job insecurity (i.e., job loss) and qualitative job insecurity (i.e., losing features of the job). Given previous research on the importance of distinguishing between the two dimensions (e.g., Jiang \& Lavaysse, 2018), future research should include both to delineate any potential differential effects on attention. Lastly, several of the relationships we tested were cross-sectional, limiting causal inference. However, the detection of interactions is not affected by the cross-sectional nature of the data and may even be harder to detect in cross-sectional data (Siemsen et al., 2010), strengthening our finding of supervisor support as a buffer between job insecurity and attention. Previous research has identified the quality of the leader-member relationship as important for job insecurity (e.g., Wang et al., 2019), which may also impact the efficacy of supervisor support for reducing job insecurity and should be incorporated in future research examining economic crises.

\section{Conclusion}

We add to the literature on work risks during economic crises by examining the role of widespread organizational cost-cutting announcements in job insecurity and suggesting supervisor support as a mechanism that organizations can use to mitigate job insecurity's effect on attention. In sum, this paper provides early findings that contribute to our understanding of the changing nature of work during the COVID19 economic crisis and identifying supervisor support that may help mitigate risks caused by large numbers of employers using cost-cutting measures in the current pandemic and in future economic crises. 


\section{Appendix 1. Mplus Code}

\section{USEVARIABLES ARE}

OrgID

ACE

Source

JIS1 JIS2 JIS3

PSS1 PSS2 PSS3

NumChi PHOUR CSIZE

Female Relation

Int_A1

Int_J1 Int_J2 Int_J3

SiAw1 SiAw2 SiAw3;

CLUSTER IS OrgID;

Define:

Center ACE PSS1 PSS2 PSS3 JIS1 JIS2 JIS3 (GRANDMEAN);

Int_A1 $=$ ACE $*$ PSS $1 ;$ !create the interaction indicators

Int_J1 = PSS1 $*$ JIS2; !create the interaction indicators

Int $\_$ $2=$ PSS2 $*$ JIS $1 ;$ !create the interaction indicators

Int_J3 = PSS3 $*$ JIS3; !create the interaction indicators

SiAw1 = 8 - SiAw1r;

SiAw2 = 8 - SiAw2r;

SiAw3 = 8 - SiAw3r;

ANALYSIS:

TYPE IS Complex;

Estimator = MLR;

Iteration $=10000$;

MODEL:

!Measurement Model

JIS by JIS1 JIS2 JIS3;

PSS by PSS1 PSS2 PSS3;

SAW by SiAw1 SiAw2 SiAw3;

Int_A by Int_A1; !measurement model for interaction factor

Int_J by Int_J1 Int_J2 Int_J3; !measurement model for interaction factor

!Structural Model

JIS on ACE (a1);

JIS on Int_A (a2);

JIS on PSS;

JIS on NumChi PHOUR

Female Relation Source CSIZE;

SAW on ACE;

SAW on JIS (b1);

SAW on PSS (b2);

SAW on Int_J (b3);

SAW on NumChi PHOUR 
Female Relation Source CSIZE;

!Covariances

ACE with CSIZE

NumChi PHOUR

Female Relation Source;

CSIZE with PSS NumChi PHOUR

Female Relation Source;

NumChi with PSS PHOUR

Female Relation Source;

PHOUR with PSS

Female Relation Source;

PSS with Female Relation Source;

Female with Relation Source;

Relation with Source;

PSS with ACE (COV1);

JIS with PSS (COV2);

!Factor Variances

JIS@1;

PSS@1;

[JIS@0];

[PSS@0];

Int_A (Var1); !Interaction variance

Int_J (Var2); !Interaction variance

MODEL CONSTRAINT:

NEW(LOW_PSS MED_PSS HIGH_PSS

ALOWS AMEDS AHIVS

BLOWS BMEDS BHIVS

INDL INDM INDH);

LOW_PSS $=-1$;

MED_PSS $=0$;

HIGH_PSS $=1$;

ALOWS $=\mathrm{a} 1+\mathrm{a} 2 *$ LOW_PSS;

AMEDS $=\mathrm{a} 1+\mathrm{a} 2 *$ MED_PSS;

AHIVS $=\mathrm{a} 1+\mathrm{a} 2 *$ HIGH_PSS;

BLOWS $=b 1+b 3 *$ LOW_PSS;

BMEDS $=$ b1 + b3*MED_PSS;

BHIVS $=b 1+b 3 *$ HIGH_PSS;

INDL $=(a 1+a 2 *$ LOW_PSS $) *(b 1+b 3 *$ LOW_PSS $)$; !Estimate conditional indirect effects

INDM $=\left(\mathrm{a} 1+\mathrm{a} 2 * \mathrm{MED} \_\mathrm{PSS}\right) *(\mathrm{~b} 1+\mathrm{b} 3 *$ MED_PSS $)$; !Estimate conditional indirect effects

INDH $=\left(\mathrm{a} 1+\mathrm{a} 2 * \mathrm{HIGH} \_\right.$PSS $) *(\mathrm{~b} 1+\mathrm{b} 3 *$ HIGH_PSS $)$; !Estimate conditional indirect effects

VAR $1=1+\operatorname{COV} 1 * * 2 ;$ ! Constraint to scale interaction factor

VAR2 $=1+\operatorname{COV} 2 * * 2 ;$ ! Constraint to scale interaction factor

OUTPUT: STANDARDIZED CINTERVAL TECH1 TECH3; 


\section{Appendix 2. Matched Pair Strategy}

Marsh et al. (2004) suggested that when forming the indicators of the latent variable interaction factors, 1) each of the multiple indicators of the independent variables should be used only once; and 2) all of the multiple indicators of the independent variables should be used. Given that cost-cutting only has one indicator, we used the indicator of supervisor support with the highest loading to meet the first recommendation from Marsh et al. (2004). However, this could violate the second recommendation.

As such, we tested the model where the indicator of cost cutting was multiplied with each of the three indicators of the perceived supervisor support scale to create three indicators of the latent interaction factor. We got very similar results. Specifically, we found cost-cutting was significantly related to job insecurity $(b=.28, S E=.14, p=.044)$. Also, perceived supervisor support moderated the relationship between job insecurity and attention $(b=-.15, S E=.07, p=.036)$ but not the relationship between cost-cutting and job insecurity $(b=.11, S E=.18$, $n s)$.

Moreover, Marsh et al. (2004) noted that there are many situations where their two recommendations may not be easily incorporated. They compared different matching strategies including the one-pair strategy, which is the strategy we adopted in the manuscript for the interaction between cost-cutting and supervisor support. They reported that the results of different matching strategies did not make much difference unless there were substantial differences between the factor loadings for different items on the same factor and the sample size is small (Marsh et al., 2004, p. 296). Since we have a large sample size and the factor loadings of the three perceived supervisor support items are similar to one another $(.88, .90, .92$, respectively), the results produced with using this one-pair strategy should be reliable.

Acknowledgments Support for this project was provided by UH Energy, Pink Petro, PESA, IPAA, and the Gulf Research Program.

Code availability The Mplus code can be found in Appendix 1.

Funding This project in part contributes to the research goals of a larger project funded by the National Academies of Sciences, Engineering and Medicine's Gulf Research Program (Grant \#: 20001182).

Data Availability The data that support the findings of this study are available on request from the corresponding author. The data are not publicly available due to privacy or ethical restrictions.

\section{Declarations}

Conflict of Interest None declared. 


\section{References}

Aikens, K. A., Astin, J., Pelletier, K. R., Levanovich, K., Baase, C. M., Park, Y. Y., \& Bodnar, C. M. (2014). Mindfulness goes to work: Impact of an online workplace intervention. Journal of Occupational and Environmental Medicine, 56(7), 721-731.

APA Dictionary of Psychology. (n.d.). Attention. Retrieved July 13, 2021, from https://dictionary.apa. org/attention

Baumeister, R. F., \& Heatherton, T. F. (1996). Self-regulation failure: An overview. Psychological Inquiry, 7(1), 1-15.

Beal, D. J., Barros, E., Macdermid, S., Beal, D. J., Weiss, H. M., Barros, E., \& Macdermid, S. M. (2005). An episodic process model of affective influences on performance. Journal of Applied Psychology, 90(6), 1054-1068.

Bernerth, J. B., \& Aguinis, H. (2016). A critical review and best-practice recommendations for control variable usage. Personnel Psychology, 69(1), 229-283.

Cham, H., West, S. G., Ma, Y., \& Aiken, L. S. (2012). Estimating latent variable interactions with nonnormal observed data: A comparison of four approaches. Multivariate Behavioral Research, 47(6), 840-876.

Cheng, G. H.-L., \& Chan, D. K.-S. (2008). Who suffers more from job insecurity? A meta-analytic review. Applied Psychology, 57(2), 272-303.

Daminger, A. (2019). The cognitive dimension of household labor. American Sociological Review, 84(4), 609-633.

de Jong, T., Wiezer, N., de Weerd, M., Nielsen, K., Mattila-Holappa, P., \& Mockałło, Z. (2016). The impact of restructuring on employee well-being: A systematic review of longitudinal studies. Work \& Stress, 30(1), 91-114.

De Witte, H., Pienaar, J., \& Cuyper, N. D. (2016). Review of 30 years of longitudinal studies on the association between job insecurity and health and well-being: Is there causal evidence? Australian Psychologist, 51(1), 18-31.

Department of Labor (2021). Unemployment insurance weekly claims.

Dimoff, J. K., \& Kelloway, E. K. (2019). With a little help from my boss: The impact of workplace mental health training on leader behaviors and employee resource utilization. Journal of Occupational Health Psychology, 24(1), 4-19.

Eisenberger, R., Stinglhamber, F., Vandenberghe, C., Sucharski, I. L., \& Rhoades, L. (2002). Perceived supervisor support: Contributions to perceived organizational support and employee retention. Journal of Applied Psychology, 87(3), 565-573.

Enders, C. K., \& Bandalos, D. L. (2001). The relative performance of full information maximum likelihood estimation for missing data in structural equation models. Structural Equation Modeling, $8(3), 430-457$.

Fisher, G. G., Chacon, M., \& Chaffee, D. S. (2019). Theories of cognitive aging and work. In B. B. Baltes, C. W. Rudolph, \& H. Zacher (Eds.), Work across the lifespan (pp. 17-45). Elsevier.

Fouad, N. A. (2020). Editor in Chief's introduction to essays on the impact of COVID-19 on work and workers. Journal of Vocational Behavior, 103441.

Heggestad, E. D., Scheaf, D. J., Banks, G. C., Monroe Hausfeld, M., Tonidandel, S., \& Williams, E. B. (2019). Scale adaptation in organizational science research: A review and best-practice recommendations. Journal of Management, 45(6), 2596-2627.

Ingels, D. (2020). Reminders may increase response rates, but is there a cost? The effects of survey reminders on suboptimal response behavior (Publication No. 28181445) [Doctoral Dissertation, University of Houston]. ProQuest Dissertations Publishing.

International Monetary Fund. (2020). The great lockdown: Worst economic downturn since the great depression. IMF Blog. https://blogs.imf.org/2020/04/14/the-great-lockdown-worst-economicdownturn-since-the-great-depression/

Jiang, L., \& Lavaysse, L. M. (2018). Cognitive and affective job insecurity: A meta-analysis and a primary study. Journal of Management, 44(6), 2307-2342.

Jin, H., Hu, Z., Li, K., Chu, M., Zou, G., Yu, G., \& Zhang, J. (2021). Study on how expert and novice pilots can distribute their visual attention to improve flight performance. IEEE Access, 9, 44757-44769. 
Jöreskog, K. G., \& Yang, F. (1996). Nonlinear structural equation models: The Kenny-Judd model with interaction effects. In G. A. Marcoulides \& R. E. Schumacker (Eds.), Advanced structural equation modeling: Issues and techniques (pp. 57-88).

Keim, A. C., Landis, R. S., Pierce, C. A., \& Earnest, D. R. (2014). Why do employees worry about their jobs? A meta-analytic review of predictors of job insecurity. Journal of Occupational Health Psychology, 19(3), 269-290.

Klein, A., \& Moosbrugger, H. (2000). Maximum likelihood estimation of latent interaction effects with the LMS method. Psychometrika, 65(4), 457-474.

Lachance-Grzela, M., \& Bouchard, G. (2010). Why do women do the lion's share of housework? A decade of research. Sex Roles, 63(11-12), 767-780.

Lam, J., Fox, K., Fan, W., Moen, P., Kelly, E., Hammer, L., \& Kossek, E. E. (2015). Manager characteristics and employee job insecurity around a merger announcement: The role of status and crossover. The Sociological Quarterly, 56(3), 558-580.

Lawrence, E. R., Halbesleben, J. R. B., \& Paustian-Underdahl, S. C. (2013). The influence of workplace injuries on work-family conflict: Job and financial insecurity as mechanisms. Journal of Occupational Health Psychology, 18(4), 371-383.

Lee, C., Huang, G.-H., \& Ashford, S. J. (2018). Job insecurity and the changing workplace: Recent developments and the future trends in job insecurity research. Annual Review of Organizational Psychology and Organizational Behavior, 5(1), 335-359.

Marsh, H. W., Wen, Z., Hau, K.-T., Little, T. D., Bovaird, J. A., \& Widaman, K. F. (2007). Unconstrained structural equation models of latent interactions: Contrasting residual- and mean-centered approaches. Structural Equation Modeling: A Multidisciplinary Journal, 14(4), 570-580.

Marsh, H. W., Wen, Z., \& Hau, K.-T. (2004). Structural equation models of latent interactions: Evaluation of alternative estimation strategies and indicator construction. Psychological Methods, 9(3), 275-300.

Mohr, G. B. (2000). The changing significance of different stressors after the announcement of bankruptcy: A longitudinal investigation with special emphasis on job insecurity. Journal of Organizational Behavior, 21(3), 337-359.

Muthén, L. K., \& Muthén, B. O. (2017). Mplus: Statistical analysis with latent variables: User's guide (Version 8).

Newman, D. A. (2014). Missing data: Five practical guidelines. Organizational Research Methods, 17(4), 372-411.

Odle-Dusseau, H. N., Hammer, L. B., Crain, T. L., \& Bodner, T. E. (2016). The influence of familysupportive supervisor training on employee job performance and attitudes: An organizational workfamily intervention. Journal of Occupational Health Psychology, 21(3), 296-308.

Preacher, K. J., \& Selig, J. P. (2012). Advantages of Monte Carlo confidence intervals for indirect effects. Communication Methods and Measures, 6(2), 77-98.

Roelfs, D. J., Shor, E., Davidson, K. W., \& Schwartz, J. E. (2011). Losing life and livelihood: A systematic review and meta-analysis of unemployment and all-cause mortality. Social Science \& Medicine, 72(6), 840-854.

Schreurs, B. H. J., Hetty van Emmerik, I., Günter, H., \& Germeys, F. (2012). A weekly diary study on the buffering role of social support in the relationship between job insecurity and employee performance. Human Resource Management, 51(2), 259-279.

Schumacher, D., Schreurs, B., De Cuyper, N., \& Grosemans, I. (2020). The ups and downs of felt job insecurity and job performance: The moderating role of informational justice. Work \& Stress, 1-22.

Selig, J. P., \& Preacher, K. J. (2009). Mediation models for longitudinal data in developmental research. Research in Human Development, 6(2-3), 144-164.

Shahzad, A. (2020). Pilots in Pakistan air crash distracted by coronavirus worry, minister says. Reuters. https://www.reuters.com/article/us-pakistan-airplane-crash-idUSKBN23V11Y. Accessed 7 Jul 2020.

Shoss, M. K. (2017). Job insecurity: An integrative review and agenda for future research. Journal of Management, 43(6), 1911-1939.

Siemsen, E., Roth, A., \& Oliveira, P. (2010). Common method bias in regression models with linear, quadratic, and interaction effects. Organizational Research Methods, 13(3), 456-476.

Sinclair, R. R., Allen, T., Barber, L., Bergman, M., Britt, T., Butler, A., Ford, M., Hammer, L., Kath, L., Probst, T., \& Yuan, Z. (2020). Occupational health science in the time of COVID-19: Now more than ever. Occupational Health Science, s41542-020-00064-3.

Sneddon, A., Mearns, K., \& Flin, R. (2013). Stress, fatigue, situation awareness and safety in offshore drilling crews. Safety Science, 56, 80-88. 
Stanton, J. M., Sinar, E. F., Balzer, W. K., \& Smith, P. C. (2002). Issues and strategies for reducing the length of self-report scales. Personnel Psychology, 55(1), 167-194.

Strully, K. W. (2009). Job loss and health in the U.S. labor market. Demography, 46(2), 221-246.

Sundfør, H. B., Sagberg, F., \& Høye, A. (2019). Inattention and distraction in fatal road crashes - Results from in-depth crash investigations in Norway. Accident Analysis \& Prevention, 125, 152-157.

Sverke, M., \& Hellgren, J. (2002). The nature of job insecurity: Understanding employment uncertainty on the brink of a new millennium. Applied Psychology, 51(1), 23-42.

Sverke, M., Hellgren, J., \& Näswall, K. (2002). No security: A meta-analysis and review of job insecurity and its consequences. Journal of Occupational Health Psychology, 7(3), 242-264.

van Dick, R., Ullrich, J., \& Tissington, P. A. (2006). Working under a black cloud: How to sustain organizational identification after a merger. British Journal of Management, 17(S1), S69-S79.

Van der Elst, T., De Witte, H., \& De Cuyper, N. (2014). The job insecurity scale: A psychometric evaluation across five European countries. European Journal of Work and Organizational Psychology, 23(3), 364-380.

Wallace, J. C., \& Chen, G. (2005). Development and validation of a work-specific measure of cognitive failure: Implications for occupational safety. Journal of Occupational and Organizational Psychology, 78(4), 615-632.

Wallace, J. C., \& Vodanovich, S. J. (2003). Workplace safety performance: Conscientiousness, cognitive failure, and their interaction. Journal of Occupational Health Psychology, 8(4), 316-327.

Wang, H.-J., Le Blanc, P., Demerouti, E., Lu, C.-Q., \& Jiang, L. (2019). A social identity perspective on the association between leader-member exchange and job insecurity. European Journal of Work and Organizational Psychology, 28(6), 800-809.

Worker Adjustment and Retraining Notification Act (WARN) of 1988 (29 USC 2100 et. seq.)

World Health Organization. (2020). Severe acute respiratory syndrome (SARS): Status of the outbreak and lessons for the immediate future. https://www.who.int/emergencies/diseases/novel-coronavirus2019/situation-reports. Accessed 19 Apr 2020.

Publisher's Note Springer Nature remains neutral with regard to jurisdictional claims in published maps and institutional affiliations. 